\title{
Erratum to: The Nice Musical Chairs model. Exploring the role of competition and cooperation between farming and herding in the formation of land use patterns in arid Afro-Eurasia
}

\author{
Andreas Angourakis ${ }^{1}$ - Matthieu Salpeteur ${ }^{1,2}$. \\ Verònica Martínez Ferreras ${ }^{1}$. \\ Josep M. Gurt Esparraguera ${ }^{1}$
}

Published online: 2 September 2017

(C) Springer Science+Business Media, LLC 2017

\section{Erratum to: J Archaeol Method Theory https://doi.org/10.1007/s10816-016-9309-8}

Unfortunately, the original version of this article contains errors in Figure 5 (main text). The corrected version is presented below. In this case, the correction mostly affects the scenarios Ao and Bo by adding a long bar at $100 \%$ of farming. All comments and interpretations remain consistent with the data presented in the corrected plots.

Fig. 5 Count of simulation runs stabilizing at different land use proportions (i.e. percentage of farming) and respective density projections (lines) for each of the eight scenarios explored.

The online version of the original article can be found at https://doi.org/10.1007/s10816-016-9309-8

Andreas Angourakis

andros.spica@gmail.com; andreas.angourakis@ub.edu

1 ERAAUB, Department of Prehistory, Ancient History, and Archaeology, University of Barcelona, C/Montalegre, 6, 08001 Barcelona, Spain

2 Ethnoecology Laboratory, Institut de Ciències i tecnologia Ambientals (ICTA), Universitat Autonoma de Barcelona, Barcelona, Spain 


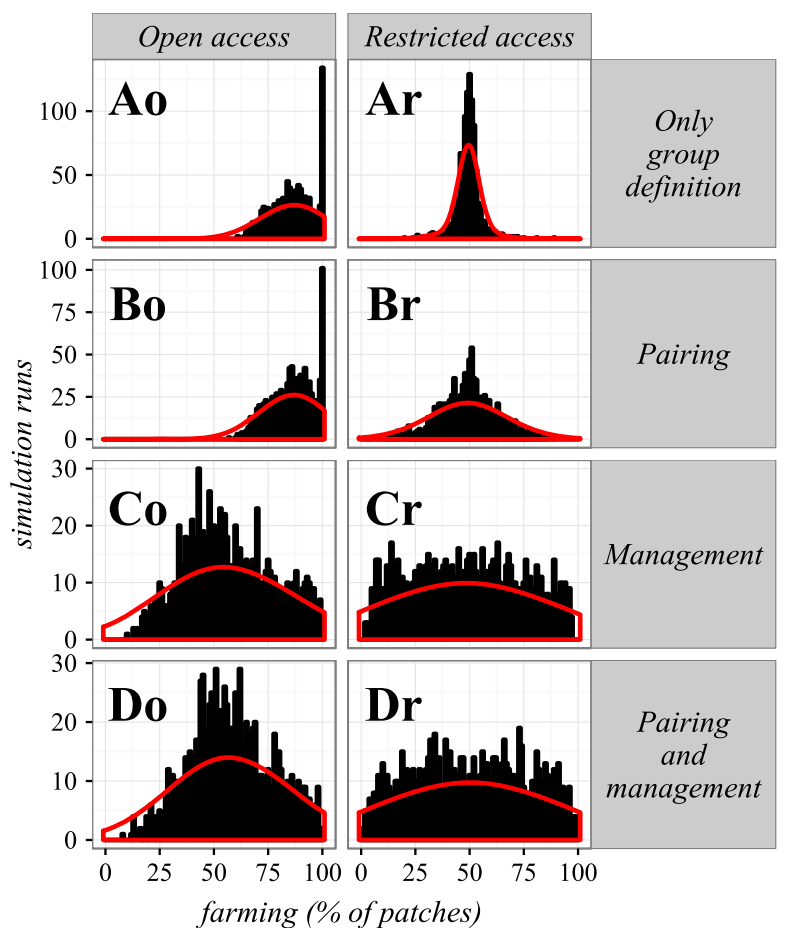

